\title{
Increased expression of erythropoietin receptor in human pterygial tissues
}

\author{
SATORU KASE ${ }^{1}$, MITSUHIKO OSAKI ${ }^{2}$, XUE-HAI JIN ${ }^{1}$, KAZUHIRO OHGAMI $^{1}$, KAZUHIKO YOSHIDA ${ }^{1}$, \\ WATARU SAITO $^{1}$, SHUJI TAKAHASHI ${ }^{3}$, KATSUYA NAKANISHI ${ }^{3}$, HISAO ITO $^{2}$ and SHIGEAKI OHNO $^{1}$ \\ ${ }^{1}$ Department of Ophthalmology and Visual Sciences, Hokkaido University Graduate School of Medicine, N15 W7, Kita-ku, \\ Sapporo 060-8638; ${ }^{2}$ Department of Microbiology and Pathology, Division of Organ Pathology, Tottori University, \\ Faculty of Medicine, 86 Nishi-cho, Yonago, Tottori 683-8503; ${ }^{3}$ Department of Pathology, Sapporo Social \\ Insurance General Hospital, 2-6-2 Atsubetsu-chuo, Sapporo 004-8618, Japan
}

Received June 14, 2007; Accepted July 26, 2007

\begin{abstract}
Erythropoietin (Epo) induces physiological activities such as cell proliferation, migration, and angiogenesis in Epo receptor (EpoR)-expressing vascular endothelial and tumor cells. Recently, it has been demonstrated that growth factor-independent proliferation is frequently observed during the cell transformation process. Pterygium is a fibrovascular proliferating tissue that includes transformed cells. The aim of this study was to examine the localization of Epo and EpoR proteins in human pterygial tissues. Eleven samples including nine pterygia and two normal bulbar conjunctivas, which were surgically excised, were studied. Formalin-fixed, paraffin-embedded tissue sections were constructed and then were examined by immunohistochemistry with anti-Epo and EpoR antibodies. Cytoplasmic immunoreactivity for EpoR was heterogeneously detected in basal and suprabasal cells of the pterygium epithelium. In the pterygium stroma, a variety of endothelial cells forming vascular cavities showed cytolasmic immunoreactivity for EpoR. In normal conjunctival epithelium, a few basal cells showed a weak homogeneous immunoreactivity for EpoR in the cytoplasm. The number of EpoR-expressing epithelial cells was much higher in the pterygium compared to the normal conjunctiva. EpoR expression was marginally detected in stromal microvessels of the normal conjunctiva. Immunoreactivity for Epo was not noted in pterygium epithelium and stroma, and in normal conjunctiva. These results suggest that the Epo-independent EpoR-signaling pathway plays a potential role in cell proliferation and angiogenesis in human pterygium.
\end{abstract}

Correspondence to: Dr Satoru Kase, Department of Ophthalmology and Visual Sciences, Hokkaido University Graduate School of Medicine, N15 W7, Kita-ku, Sapporo 060-8638, Japan

E-mail: kaseron@med.hokudai.ac.jp

Key words: erythropoietin receptor, epithelium, microvessels, pterygium

\section{Introduction}

Pterygium represents an epithelial and fibrovascular configuration on the ocular surface which is continuous with the conjunctiva. Pathobiology of the pterygium reveals neoplasia-like behaviors such as cell proliferation, invasion to the cornea, and recurrence after resection. We recently demonstrated that pterygium epithelial cells showed cellular transition from quiescence to the proliferative state (1) possibly through induction of $\beta$-catenin transcription factor (2) and cyclin D1, a G1 cyclin (3). Detection of microsatellite instability and loss of heterozygosity, two events transpiring in tumor cells or in premalignant cells, constitutes strong evidence of the presence of transformed cells in the pterygium tissue (4-6). In fact, squamous cell carcinoma and carcinoma in situ rarely arise from pterygium (7). These results support the hypothesis that pterygium is a neoplastic benign lesion, as previously proposed (4).

Angiogenesis is defined as the formation of new blood vessels from pre-existing vasculature and underlies physiological processes including growth and differentiation, as well as neoplastic conditions (8). The process of vascularization involves the activation of angiogenic factors and several signaling pathways for endothelial cell migration. It has been demonstrated that microvessel density is significantly higher in pterygium stroma than in normal conjunctiva (9), indicating that pterygium is a vascular-rich tissue, and angiogenesis plays an important role in its pathogenesis and development.

Erythropoietin (Epo) was first described as a glycoprotein produced exclusively in fetal liver and adult kidney which acts as a major regulator of erythropoiesis (10). Epo receptor (EpoR) is a member of the type I cytokine receptor family which modulates cell growth, apoptosis, and differentiation $(11,12)$. Epo shows angiogenic activity in EpoR-expressing vascular endothelial cells, which stimulates proliferation, migration, and angiogenesis (13). Furthermore, EpoR is upregulated in a variety of malignant solid neoplasias $(12,14)$. We recently demonstrated that EpoR is expressed in Merkel cell carcinoma cells and intratumoral microvessels (15). The aim of this study was to examine the expression of Epo and 
EpoR in human normal conjunctiva and pterygium tissues by immunohistochemistry.

\section{Materials and methods}

Operative specimens. Eight patients (nine eyes) with primary pterygia who underwent the bare-sclera procedure were enrolled in this study. The pterygium head and body were confirmed, and excised tissue was immediately placed on sterilized filter paper. Normal bulbar conjunctival tissues were obtained from two patients during cataract surgery without any ocular surface disorder. The tissues were then fixed in $4 \%$ paraformaldehyde. After fixation, slides were washed in phosphate-buffered saline, and processed for paraffin sectioning. Informed consent was obtained according to the Declaration of Helsinki. All human experiments conformed to the ethics committee of Hokkaido University Graduate School of Medicine.

Immunohistochemistry. Dewaxed paraffin sections were immunostained using the streptavidin-biotin peroxidase complex method. Formalin-fixed, paraffin-embedded serial tissue sections were cut at a thickness of $4 \mu \mathrm{m}$, and endogenous peroxidase activity was inhibited by immersing the slides in $0.3 \%$ hydrogen peroxide in methanol for $30 \mathrm{~min}$. As a pretreatment, microwave-based antigen retrieval was performed in $10 \mathrm{mM}$ citrate buffer ( $\mathrm{pH}$ 6.0). Then, nonspecific binding of the primary antibody was blocked by incubating the slides in the blocking serum for $20 \mathrm{~min}$. The slides were serially incubated with anti-Epo (dilution 1:50, R\&D Systems), and EpoR (1:100, Santa Cruz Biotechnology, Inc., CA, USA) antibodies overnight at $4^{\circ} \mathrm{C}$, followed by the secondary antibody and biotin-streptavidin complex for $30 \mathrm{~min}$ each at room temperature. Immunoreactions were visualized with diaminobenzidine, and the sections were counterstained with hematoxylin. To examine the specificity of immunostaining, the primary antibody was replaced with mouse normal $\mathrm{IgG}$ or Tris-buffered saline. Control slides were invariably negative for immunostaining. As a positive control for Epo, malignant melanoma tissues of the skin were examined (16). Merkel cell carcinoma of the eyelid tissues served as a positive control for EpoR as previously described

\section{EpoR}

Epo

\section{Pterygium epithelium}

\section{Pterygium stroma}

\section{Normal conjunctiva}
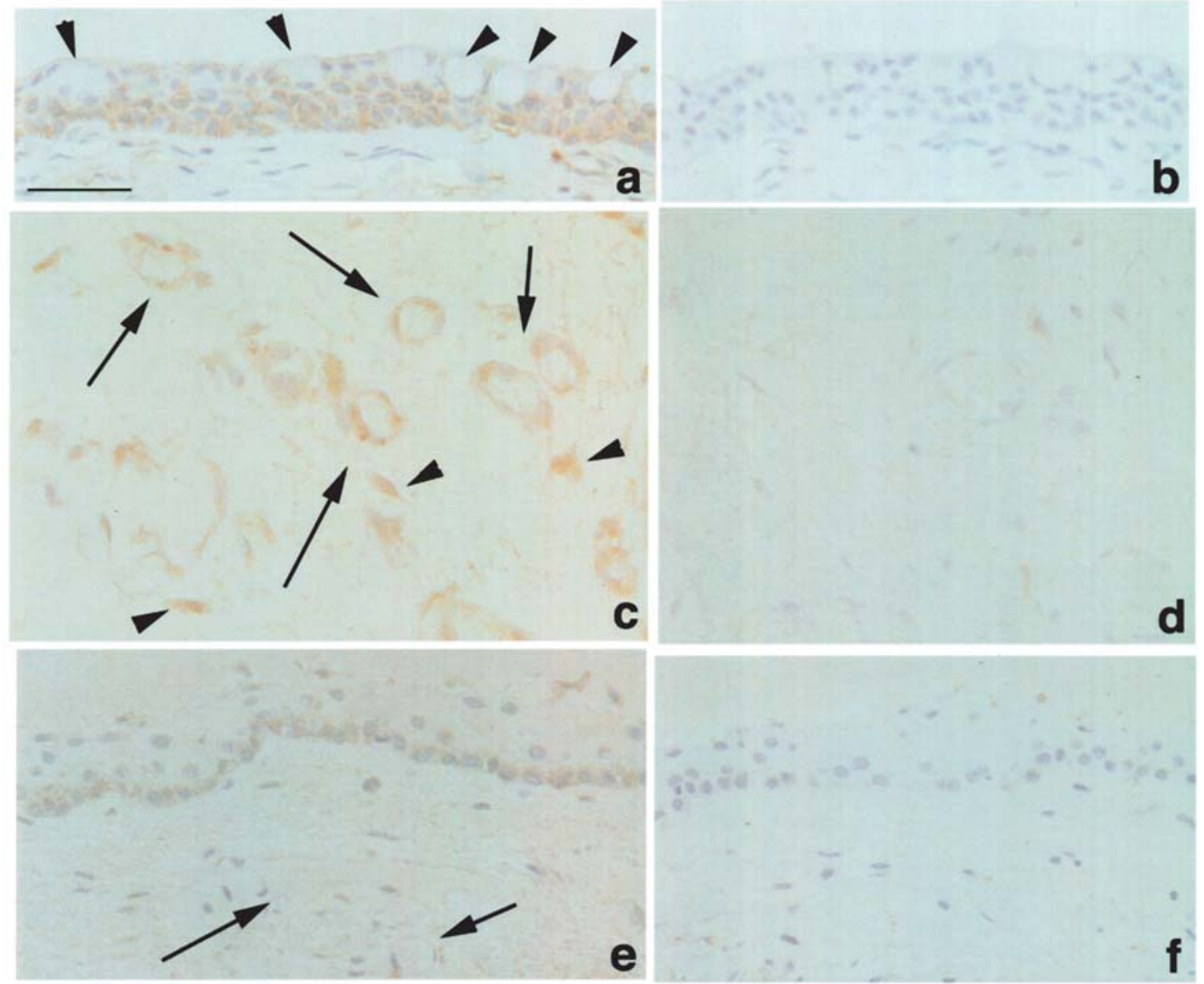

Figure 1. Immunoreactivity for erythropoietin (Epo) receptor (EpoR) (a,c,e) and Epo (b,d,f) in human pterygium epithelium (a,b) and stroma (c,d), and normal conjunctiva (e,f). Cytoplasmic immunoreactivity for EpoR is detected in basal and supra-basal cells of the pterygium epithelium (a). EpoR expression is not observed in goblet cells intermingled in the superficial layer (a, arrowheads). In the pterygium stroma, a variety of endothelial cells forming vascular cavities show cytoplasmic immunoreactivity for EpoR (c, arrows). The immunoreactivity is also noted in several nonvascular stromal fibroblasts (c, arrowheads). In normal conjunctival epithelium, a few basal cells show a weak homogeneous immunoreactivity for EpoR in the cytoplasm (e). EpoR expression is not detected in normal conjunctival stromal microvessels (e, arrows). Immunoreactivity for Epo is not noted in pterygium epithelium (b), and stromal microvessels (d), and in the normal conjunctiva (f). Bar, $50 \mu \mathrm{m}$. 
Table I. Immunopositive cells (\%) for erythropoietin (Epo) receptor (EpoR) and Epo in human normal conjunctiva and pterygium tissues.

\begin{tabular}{lccc}
\hline & \multicolumn{2}{c}{ EpoR } & Epo \\
\cline { 2 - 3 } & Epithelium & Stromal microvessels & \\
\hline Conjunctiva & 15.2 & 1.0 & 0 \\
Pterygium head & 57.5 & 52.8 & 0 \\
Pterygium body & 53.5 & 40.0 & 0 \\
\hline
\end{tabular}

(15). We counted at least 100 epithelial and/or stromal endothelial cells in one or two microscopic fields from the examined tissues. Positive-staining cells were noted by their labeling index as a percentage (\%) in each specimen, and the measurements were averaged.

\section{Results}

Histopathological findings demonstrated that pterygium epithelium consisted of squamous metaplasia and goblet cell hyperplasia (3). Cytoplasmic immunoreactivity for EpoR was heterogeneously detected in basal and suprabasal cells of all pterygium tissues (Fig. 1a). EpoR expression was not observed in goblet cells intermingled in the superficial layer (Fig. 1a, arrowheads). In the pterygium stroma, a variety of endothelial cells forming vascular cavities showed cytoplasmic immunoreactivity for EpoR (Fig. 1c, arrows). The immunoreactivity was also noted in several nonvascular stromal fibroblasts (Fig. 1c, arrowheads). In normal conjunctival epithelium, a few basal cells showed a weak homogeneous immunoreactivity for EpoR in the cytoplasm (Fig. 1e). The number of EpoR-expressing epithelial cells was less marked in the normal conjunctiva compared to the pterygia (Table I). EpoR expression was marginally detected in the normal conjunctival stromal microvessels (Fig. 1e, arrows). The number of EpoR-immunopositive cells showed no significant difference between pterygium head and body. Immunoreactivity for Epo was not noted in pterygium epithelium (Fig. 1b) and stroma (Fig. 1d), and in normal conjunctiva (Fig. 1f). The rate of EpoR- and Epo-immunopositive cells is summarized in Table I. Epo was strongly expressed in the cytoplasm of malignant melanoma cells as a positive control (data not shown).

\section{Discussion}

We clearly demonstrated that cytoplasmic immunoreactivity for EpoR was detected in pterygium epithelial cells, whereas the immunoreactivity was less marked in normal conjunctival epithelium. These results suggest that EpoR is upregulated in the pterygium epithelia as shown in a variety of systemic neoplastic lesions $(12,14,15)$. Acs et al demonstrated that Epo bound to EpoR was expressed in cancer cells and activated the signal transducer and activator of transcription (STAT) 5 and nuclear factor- $\mathrm{B}$ signaling transduction pathways (14). Furthermore, activation of the pathways subsequently leads to cancer cell proliferation (17) and migration (18). Taken together, increased expression of EpoR in pterygium epithelium is possibly correlated with epithelial proliferation and invasion through the EpoR-signaling pathway.

In the pterygium stroma, a variety of endothelial cells showed cytoplasmic immunoreactivity for EpoR, while EpoR expression was less marked in normal conjunctival stromal vessels. This indicates that EpoR is induced in stromal microvessels of pterygium tissues. It was reported that the binding of Epo to EpoR-expressing vascular endothelial cells stimulates proliferation, migration, and angiogenesis (13). Collectively, these findings suggest that EpoR accumulation in pterygium endothelial cells reflects its angiogenic activity.

In contrast to EpoR, Epo immunoreactivity was not detected in pterygial and conjunctival tissues. It is known that growth factor-independent proliferation is frequently observed during the cell transformation process (19). In erythroid cells, several mechanisms lead to Epo independence, such as alterations of the EpoR, autocriny, and apoptosis resistance. Indeed, it was demonstrated that there must be transformed cells in the pterygium tissue (4). EpoR was constitutively activated either by interaction with the env protein encoded by the spleen focus forming virus (SFFV) component of the Friend virus (20) or by a point mutation in the exoplasmic domain of the EpoR (21). Therefore, cell proliferation and angiogenesis in EpoR-expressing pterygium tissues might be correlated with Epo-independent mechanisms.

In this study, several nonvascular stromal fibroblasts also showed EpoR immunoreactivity. This suggests that not only pterygium endothelial cells, but also fibroblasts, take part in angiogenesis via the EpoR-signaling pathway.

Recent clinicopathological analysis implies that hypoxia plays an important role in pterygium pathogenesis (22). Moreover, it was recently suggested that EpoR is upregulated by ischemia or hypoxia $(23,24)$. In fact, we demonstrated that EpoR expression was noted in ischemic ocular tissues (25). These results indicate that the upregulation of EpoR observed in this study is correlated with a potential ischemic/hypoxic condition in pterygium tissues. Clarification of the mechanism in the regulation of EpoR expression may contribute to a novel therapeutic targeting for pterygium angiogenesis and proliferation.

\section{Acknowledgements}

This study was supported by a Grant for Research on Sensory and Communicative Disorders from The Ministry of Health, Labor, and Welfare, and by Grants-in-aid for Scientific Research from The Ministry of Education, Culture, Sports, Science, and Technology (MEXT), Japan.

\section{References}

1. Kase S, Kitaichi N, Furudate N, Yoshida K and Ohno S: Increased expression of mucinous glycoprotein KL-6 in human pterygium. Br J Ophthalmol 90: 1208-1209, 2006.

2. Kase S, Osaki M, Sato I, Takahashi S, Nakanishi K, Yoshida K, Ito $\mathrm{H}$ and Ohno $\mathrm{S}$ : Immunolocalization of E-cadherin and \{beta\}-catenin in human pterygium. Br J Ophthalmol, 2007 Mar 14 [Epub ahead of print].

3. Kase S, Takahashi S, Sato I, Nakanishi K, Yoshida K and Ohno S: Expression of p27(KIP1) and cyclin D1, and cell proliferation in human pterygium. Br J Ophthalmol 91: 958961, 2007. 
4. Spandidos DA, Sourvinos G, Kiaris H and Tsamparlakis J: Microsatellite instability and loss of heterozygosity in human pterygia. Br J Ophthalmol 81: 493-496, 1997.

5. Detorakis ET, Drakonaki EE and Spandidos DA: Molecular genetic alterations and viral presence in ophthalmic pterygium. Int J Mol Med 6: 35-41, 2000.

6. Detorakis ET, Sourvinos G, Tsamparlakis J and Spandidos DA: Evaluation of loss of heterozygosity and microsatellite instability in human pterygium: clinical correlations. Br J Ophthalmol 82: 1324-1328, 1998.

7. Lee GA and Hirst LW: Ocular surface squamous neoplasia. Surv Ophthalmol 39: 429-450, 1995.

8. Folkman J and Klagsbrun M: Angiogenic factors. Science 235: 442-447, 1987.

9. Aspiotis M, Tsanou E, Gorezis S, Ioachim E, Skyrlas A, Stefaniotou M and Malamou-Mitsi V: Angiogenesis in pterygium: study of microvessel density, vascular endothelial growth factor, and thrombospondin-1. Eye, 2006 Jun 23 [Epub ahead of print].

10. Fisher JW: Erythropoietin: physiology and pharmacology update. Exp Biol Med 228: 1-14, 2003.

11. Lacombe $C$ and Mayeux P: The molecular biology of erythropoietin. Nephrol Dial Transplant 14 (suppl 2): 22-28, 1999.

12. Hardee ME, Arcasoy MO, Blackwell KL, Kirkpatrick JP and Dewhirst MW: Erythropoietin biology in cancer. Clin Cancer Res 12: 332-339, 2006.

13. Yamaji R, Okada T, Moriya M, Naito M, Tsuruo T, Miyatake K and Nakano Y: Brain capillary endothelial cells express two forms of erythropoietin receptor mRNA. Eur J Biochem 239: 494-500, 1996.

14. Acs G, Acs P, Beckwith SM, Pitts RL, Clements E, Wong K and Verma A: Erythropoietin and erythropoietin receptor expression in human cancer. Cancer Res 61: 3561-3565, 2001.

15. Kase S, Yoshida K, Osaki M, Adachi H, Ito H and Ohno S: Expression of erythropoietin receptor in human Merkel cell carcinoma of the eyelid. Anticancer Res 26: 4535-4537, 2006.

16. Kumar SM, Acs G, Fang D, Herlyn M, Elder DE and Xu X: Functional erythropoietin autocrine loop in melanoma. Am J Pathol 166: 823-830, 2005.
17. Feldman L, Wang Y, Rhim JS, Bhattacharya N, Loda M and Sytkowski AJ: Erythropoietin stimulates growth and STAT5 phosphorylation in human prostate epithelial and prostate cancer cells. Prostate 66: 135-145, 2006.

18. Lester RD, Jo M, Campana WM and Gonias SL: Erythropoietin promotes MCF-7 breast cancer cell migration by an ERK/ mitogen-activated protein kinase-dependent pathway and is primarily responsible for the increase in migration observed in hypoxia. J Biol Chem 280: 39273-39277, 2005.

19. Barnache S, Mayeux P, Payrastre B and Moreau-Gachelin F: Alterations of the phosphoinositide 3-kinase and mitogenactivated protein kinase signaling pathways in the erythropoietin-independent Spi-1/PU.1 transgenic proerythroblasts. Blood 98: 2372-2381, 2001.

20. Longmore GD and Lodish HF: An activating mutation in the murine erythropoietin receptor induces erythroleukemia in mice: a cytokine receptor superfamily oncogene. Cell 67: 1089-1102, 1991.

21. Yoshimura A, Longmore G and Lodish HF: Point mutation in the exoplasmic domain of the erythropoietin receptor resulting in hormone-independent activation and tumorigenicity. Nature 348: 647-649, 1990.

22. Lee JK, Song YS, Ha HS, Park JH, Kim MK, Park AJ and Kim JC: Endothelial progenitor cells in pterygium pathogenesis. Eye, 2006 May 26 [Epub ahead of print].

23. Genc S, Koroglu TF and Genc K: Erythropoietin and the nervous system. Brain Res 1000: 19-31, 2004

24. Shein NA, Horowitz M, Alexandrovich AG, Tsenter J and Shohami E: Heat acclimation increases hypoxia-inducible factor 1alpha and erythropoietin receptor expression: implication for neuroprotection after closed head injury in mice. J Cereb Blood Flow Metab 25: 1456-1465, 2005.

25. Kase S, Saito W, Ohgami K, Yoshida K, Furudate N, Saito A, Yokoi M, Kase M and Ohno S: Expression of erythropoietin receptor in human epiretinal membrane of proliferative diabetic retinopathy. Br J Ophthalmol, 2007 May 23 [Epub ahead of print]. 